\title{
Construction of Authorial Identity in Academic Research Articles: From the Perspective of Evidentiality
}

\author{
Wenxiu Song \\ Correspondence: Wenxiu Song, School of Foreign Languages, Southwest University of Political Science and Law, \\ 401120, Chongqing, China. E-mail: viviansong1@163.com
}

Received: July 28, 2019

Accepted: October 2, 2019

Online Published: January 12, 2020

doi:10.5430/elr.v9n1P1

URL: https://doi.org/10.5430/elr.v9n1P1

\begin{abstract}
This paper investigates the construction of authorial identity in academic research articles from the perspective of evidentiality through analyzing 12 academic research articles selected at random from Applied Linguistics, Corpus Pragmatics and Journal of Pragmatics. It is found that the rational employment of evidentials in academic research articles contributes to the construction of authorial identity from the respect of author's authority and reliability, which is reflected in the choice of evidentials.
\end{abstract}

Keywords: authorial identity, academic research article, evidentiality, evidentials

\section{Introduction}

The construction of identity is a process of constant self-definition and self-construction (Marchand \& Parpart, 2003:81), on the ground that one's knowledge of the identity of himself/ herself and others are shaped by specific history and culture rather than something predetermined and fixed. As a special kind of identity, authorial identity is constructed through the communication between author and readers. A great many studies on authorial identity in academic discourse have been conducted by scholars in the field of linguistics, most of which are based on the analysis of first person pronoun ('I' or 'we') considered the most explicit marker of authorial identity. For instance, Hyland (2002: 111-117) investigates the six functions of the first person pronoun in academic discourse; Tang and John (1999:23-39) explore the use of first person pronoun in the thesis writing of university students in Singapore. Besides such explicit markers, in fact, implicit expressions are also employed in academic writing to express the authorial identity and views. From the previous studies, it can be seen that there is a variety of linguistic resources for the construction of authorial identity in academic discourse (e.g. Matsuda, 2007; Ouellette, 2008; Hyland, 2001a, 2002b, 2005b; Ivanic, 1998, 2001; Tang \& John, 1999, etc.). However, few of them involve evidentiality which is pervasive in academic discourse and closely related to authorial identity in respect of the information source and the author's commitment to the truth of propositions (Yang, 2012: 140-146). From this point of view, this study focuses on how evidentiality contributes to the construction of authorial identity in academic research articles and facilitates the interaction between the author and the readers. It is hoped that this study dealing with the relationship between evidentiality and the construction of authorial identity will inspire the writing of academic research article.

\section{Research Methods}

\subsection{Data Collection}

This study takes the academic research articles as the research object and selects 12 academic articles randomly from Applied Linguistics, Journal of Pragmatics and Corpus Pragmatics released from 2012 to 2018, totaling 94137 words, to build a corpus.

\subsection{Research Procedures}

Both quantitative and qualitative methods are adopted to carry out this study which falls into two stages. The first stage: corpus annotation and count. The corpus collected is annotated manually based on the classification of evidentiality in this study, namely, belief, inference, hearsay, reliability and expectation, then the annotated corpus is retrieved and counted by the software Antconc for the number and frequency of different kinds of evidentials. Repetitive check and correction are assigned to reduce errors. The second stage: the analysis and explanation of the statistical results. Through the analysis of the statistics, the relationship between evidentiality and the construction of authorial identity can be found out. 


\section{Authorial Identity}

The authorial identity refers to the different self-hood constructed by the author in the process of interaction with the readers and the possibilities for self-hood in the social context such as belief and ideology (Ivanic, 1998). As a special discourse, academic research article is a kind of theoretical paper that conveys research findings following the research of academic issues in a specific field. Like other forms of communication, academic article is an act of showing identity (Ivanic, 1998), a representation of self-hood. Ivanic (1998) provides an influential framework for the author to present self-hood and self as author expressed by text. The framework includes four interrelated aspects of the authorial identity: autobiographical self, discoursal self, self as author, possibilities for self-hood in the socio-cultural and institutional context. Autobiographical self is the identity shaped by author's previous social and textual experience and associated with 'a writer's sense of their roots, of their disposition to behave in certain ways (Ivanic, 1998:23)'; discoursal self refers to the image an author consciously or unconsciously projects in a particular text (Tang \& John, 1999); self as author, is associated with the writer's stance in the writing; possibilities for self-hood refers to the abstract prototypical identities available to the author in the writing in socio-cultural context.

In the light of Ivanic's taxonomy of writer's identity, a large number of research studies sprang out (e.g. Tang \& John, 1999; Abasi, Akbari, \& Graves, 2006; Hyland, 2002a; Ouellette, 2008) in addressing the self-referencing and other issues in academic writing. Inspired by Ivanic's studies, Tang and John find that author is acting three possible roles when producing a piece of writing, namely, societal role, discourse role and genre role, arguing that there is room for the negotiation of authorial identity in academic writing. The societal role is inherent to a person such as the role of a husband, wife, father, mother, Chinese, etc.; a discourse role is the identity established by author's engaging in a particular discourse community and thus it is discourse specific; a genre role is constructed on a genre-specific basis in discourse community (Tang \& John, 1999). Such a classification makes sense, while the discourse role and genre role overlap in some respects, which brings about a blurred line between them.

The construction of authorial identity is reflected in a variety of language resources, among which the first person pronoun draws the most researchers. Tang and John (1999) investigate the use of first person pronoun in the postgraduates' academic writing of a university in Singapore and sort out six authorial identities constructed by the first person pronoun $I$, specifically, representative, guide, architect, recounter of research process, opinion holder and originator. By examining the use of first person pronouns in undergraduates' (second language learners) thesis, Hyland (2002a) discusses how the author shows his/ her identity and concludes that the use of in academic writing is problematic due to the connotation of authority conveyed thereby. In fact, besides such explicit marker as first person pronoun, implicit and indirect means are also taken by the author to produce academic discourse, such as the author, the present author $(s)$, and even some inanimate and abstract subjects like the study/article/ paper, to express the identity and view of the author indirectly.

\section{Evidentiality}

As to the question of what exactly evidentiality is, no consensus has been reached so far in the field of linguistics. Linguist Palmer (2001) suggests that evidentiality is a kind of modality and proceeds his research on evidentiality from typology. From the perspective of cognition, Chafe (1986) regards evidentiality as part of exploring the differences between spoken and written English. In Mushin's point of view (2001), evidentiality is a cognitive style of presenting information and author has the epistermological consideration of the information source and interaction setting before he makes evidential choice. While Aikhenvald and Dixon (2003) work on the evidential system of various languages, especially those unpopular languages.

It is generally accepted that evidentiality can be defined narrowly and broadly. In a narrow sense, evidentiality refers to the grammatical reference to information source (Delancey, 2001) and concerns with 'source of knowledge'. Correspondingly, evidentials (or evidential marker) is defined as a set of suffixes that express 'source of knowledge' and the degree of certainty (Boas, 1947). Evidentiality, broadly speaking, involves not only the 'source of knowledge', but also 'speaker's/writer's attitude towards the knowledge/ commitment to the knowledge' (Chafe, 1986). The speaker/writer will demonstrate knowledge with an explanation of reliability if he is unsure about its authenticity. According to Chafe and Nichols, evidentials is a marker of the source and reliability of the knowledge (Chafe \& Nichols, 1986). While it is interpreted as a marker showing the reliability of knowledge from four aspects by Mithun (1986:89-112): sources of evidence, degree of precision, probability and expectation.

Such different definitions bring forth various classifications of evidentials. According to Chafe and Nichols (1986), evidentials is classified into belief, inference, hearsay, general expectation and degree of reliability. While Willett (1988) proposes a more detailed classification. In his opinion, evidential is generalized into two types, direct and indirect. The former includes the visual sense, auditory sense, and/or other senses, while the latter consists of 
reported evidence and inferring evidence. Reported evidence may be specifically marked as secondhand or third hand (hearsay), or as part of the oral literature (folklore); inferring evidence may be marked as involving either observable evidence (results) or a mental construct only (reasoning). Bussmann (1996: 157) argues that evidentials can be divided into three types, that is, the visual (sensory), hearsay (reported) and the inferential. In addition, in Evidentiality, Aikhenvald (2004:63-64) states that evidentials includes six categories: visual, non-visual sensory, inference, assumption, hearsay and quotative. Based on the knowledge of evidentiality and the above classification, this study classifies evidentials into five types: belief, inference, hearsay, reliability and expectation.

Belief evidentials refers to the knowledge or information originating from the speaker's subjective judgment, guessing or even imagination (Wang \& Yu, 2011). Chafe (1986) views belief as a mode of knowing and believes that it is relied on something rather than sheer evidence. It is quite subjective given that speaker may believe something under the influence of his cultural community or his belief in someone, thus detracting from the evidentiality. Typically, it is realized by the author/I/ We suggest/ believe/ think/ hold..., it can be suggested... and so forth. For example:

Example 1: Therefore, I suggest, when a speaker uses AL, it generates a not-exactly implicature. (Korat, 2018)

In example 1, belief evidentials is embodied in the phrase I suggest...... with subjectivity, by which the author puts forward his own view.

Inferring evidentials means that the information is inferred from evidence instead of individual experience. It falls into inference and assumption. Aikhenvald (2004: 63-64) believes that evidentials of inference includes induction and deduction, involving an inferential process based on visible or tangible evidence, while assumption refers to an inferential process based on logical reasoning, sheer assumption or general knowledge. In English academic research articles, inferring evidentials is primarily realized by modal verbs and modal adjuncts, such as certainly, likely, clearly, it can be inferred that, etc. For example:

Example 2: In the cases examined, it can be inferred that for most participants, the speaker's meaning of the three utterances differed from the computed utterance meaning. (Givoni, Giora \& Bergerbest, 2013)

In example 2, can serves as an inferential evidentials based on case examine, or in other words, on the process of induction. A well-founded induction generally has a high degree of reliability.

Hearsay evidentials refers to direct quotation or reporting of existing information. Information may be either personal experience or obtained from others. The employment of hearsay evidentials helps to enhance the objectivity and scientificity of academic articles and facilitates readers' retrieval and verification of the information. Realization of hearsay evidentials includes it is argued/ said/ assumed that, xx argue (s)/ claim (s), according to, etc. For example:

Example 3: According to Hyland (2005: 37), "metadiscourse is the cover term for the self-reflective expressions used to negotiate interactional meanings in a text, assisting the writer (or speaker) to express a viewpoint and engage with readers as members of a particular community". (Malmström, 2014)

In example 3, instead of giving the definition of metadiscourse directly, the author engages Hyland's explanation. The use of hearsay evidentials according to improves readers' understanding of metadiscourse and undermines the author's subjectivity meanwhile. It is thus clear that the employment of hearsay evidentials is more convincing than giving the author's opinion directly.

Reliability evidentials is used to describe the truthfulness of a piece of knowledge. The degree of reliability of the knowledge can be indicated by the use of different modes of knowing which implies something about reliability (Chafe, 1986: 266). Different degrees of reliability can be indicated by various evidentials, specifically, modal verbs and adverbs in English, such as might, may, probable, possibly, etc. In academic research article, reliability evidentials will appear where the author is uncertain of the information or proposes a viewpoint contrary to the findings of the previous studies. For example:

Example 4: They may appear in close proximity with reportive evidential uses of the Italian conditional mood. (Rocci, 2012)

In example 4, may indicates a possibility with uncertainty. They does not necessarily appear or appear under the condition in close proximity with. In order to maintain the objectivity and rigorousness of academic research article, it is necessary to employ such an evidentials to mitigate the absoluteness of the author and leave adequate leeway for the researches of the author.

Expectation evidentials concerns with whether the facts described in the discourse match with the expectations held 
by the author. Expectation evidentials is represented by markers like nevertheless, however, in fact, etc.

Example 5: This is, of course, the basis of much research in Second Language Acquisition.

Here, in example 5 of course indicates that the knowledge This is the basis of much research in Second Language Acquisition is matched with the expectation.

Table 1 below displays the classification and realizations of evidentials in academic research articles.

Table 1. Evidentials in Academic Research Articles

\begin{tabular}{cl}
\hline Evidentials & \multicolumn{1}{c}{ Realization of Evidentials in Academic Research Articles } \\
\hline belief & The author/I/We suggest/ believe/ think/hold, it can be suggested, etc. \\
inference & It can be inferred that, appear, certainly, likely, clearly, etc. \\
hearsay & It is argued/ said/ assumed that, xx argue $(s) /$ claim $(s)$, according to, etc. \\
reliability & Might, may, probable, possibly, etc. \\
expectation & Nevertheless, however, in fact, etc.
\end{tabular}

\section{Construction of Authorial Identity and Evidentiality in Academic Research Articles}

\subsection{Evidentiality and the Author's Authority}

The establishment of authority functions as a cornerstone in academic research articles. In this study, authority is regarded as one of the aspects of authorial identity, showing the author's responsibility and commitment to the content of the academic articles, as well as the author's knowledge and professionalism in a specific field. It can be further elaborated from the 'source of knowledge' and 'author's attitude towards knowledge' as follows.

\subsection{1 'Source of Knowledge' and Author's Authority}

First of all, choosing the right and reliable information source contributes to strengthen the author's credibility. As mentioned above, the 'source of knowledge' is the primary content of evidentiality whose basic significance lies in expressing the source of information, whether from a broad or narrow sense. If the source of a piece of knowledge is not acknowledged, the author will be questioned for his authority. That is to say, a trustworthy source is conducive to the establishment of the author's authority. For example:

Example 6: Partington (2007:1564) suggests that the mother is implying a reversed evaluation, i.e. "hatred" rather than "love" (Dynel, 2017)

In example 6, the author highlights that the knowledge comes from Dynel and Marta rather than his arbitrary assumption, providing the readers with the information that his research output is brought forth based on previous studies which can be retrieved. However, the source of the knowledge is not always clear in that the author may employ some language strategies to cover up or skip the source of the information for specific purpose (s). Is the author's authority thus spoiled? The answer is No, which can be substantiated as follows.

Example 7: It is believed that time and space can affect one's attitude. (Chen \& Baker, 2016)

In example 7, the agent of the hearsay evidentials believe is omitted by virtue of passive voice and the objectivity of the article is improved to some extent. Xx believe( $s$ ) gives the readers an impression that the author has nothing to do with the information following believe, while it is believed spotlights the content of the information and eclipses 'who believes'. The omission of the source of the knowledge shortens the distance between readers and the author and thus creates a harmonious academic atmosphere. Therefore, far from spoiling the authority of the author, the rational use of language strategies such as it is believed promotes the interaction between author and readers.

In academic research articles, hearsay evidentials is chiefly realized by the report of the researches of authoritative scholars. What's more, the source of the information rather than the information itself is emphasized wherever hearsay evidentials is used. It is essential for the author to establish authority by bringing up his/ her new insights based on previous studies and select the source of information that are more likely to be recognized by readers, on the ground that readers are more inclined to accept the views and opinions proposed by authoritative scholars.

\subsection{2 'Author's Attitude towards Knowledge' and Author's Authority}

'The author's attitude towards knowledge' has two types, namely, sure and unsure. The former means that the author is sure about the knowledge, that is, the truth value of the proposition is determinate, while the latter means that the author holds an uncertain attitude towards the knowledge, which requires the author's degree of commitment to be 
attached to the proposition. For example:

Example 8: This study seeks to complement previous research by investigating patterns in the L2 expression of epistemicity according to three large lexico-grammatical categories (adverbial, adjectival, and verbal expressions) across four different speech types. (Gablasova, Brezina, Mcenery, et al., 2015)

Example 9: Maybe this study seeks to...

Example 10: This study probably seeks to...

In example 8, the author is sure about the main content of study, so the proposition is projected directly. Example 9 and 10 are produced as a result of minor modifications made to example 8. Under such circumstances, the content of the two propositions comes from inference and assumption which may be true or false. As a modal verb with low value, the adverb may and probably act as hedges as stated in the Model of Academic Interaction by Hyland and make the proposition rigorous (Hyland, 1996). From the above examples, it can be concluded that the author of an academic research article is not always able to give definite academic opinions, which shows author's respect for knowledge as well as his undertaking of academic responsibility. Besides, the degree of commitment of the author contributes to ensure the preciseness of the knowledge, thus maintaining and consolidating the authority of the author.

In academic research articles, while inferring evidentials and reliability evidentials can showcase the author's dubious attitude towards the information, they can, on the other hand, fulfill their pragmatic functions in some circumstances especially when the findings are different from those of the previous researches, specifically, the use of inferring evidentials and reliability evidentials shows a modest and rigorous academic attitude, and hence improves the authority of the author.

\subsection{Evidentiality and Author's Reliability}

Reliability is an important criterion to judge the value of an academic research article. The author's reliability is a make-or-break factor for an article given that readers generally tend to believe the information provided by a reliable author. As a language strategy in academic writing, whether the evidentiality is employed properly affects the reliability of the author directly.

The sound employment of different kinds of evidentials conduces to improve the reliability of the author. In this study, it is found that the frequency of each type of evidentials, namely, belief, inference, hearsay, reliability and expectation, does not necessarily correspond to its degree of reliability, that is, high frequency does not imply high degree of reliability, and the converse is true as well. As is shown in table 2 which is dealt with by Antconc, hearsay is used most frequently $(9.80 \%)$ ), followed by inference $(3.2 \%$ ), while belief $(0.70 \%$ ), reliability $(1.41 \%$ ) and expectation $(2.16 \%$ ) are less favored, which is closely related to the emphasis of objectivity and credibility in academic research articles (see Table 2).

Table 2. The Specific Use of Evidentials in Academic Research Articles

\begin{tabular}{lllllll}
\hline Corpus & $\begin{array}{l}\text { Frequency } \\
\text { (total) }(\%)\end{array}$ & Belief $(\%)$ & $\begin{array}{l}\text { Inference } \\
(\%)\end{array}$ & $\begin{array}{l}\text { Hearsay } \\
(\%)\end{array}$ & $\begin{array}{l}\text { Reliability } \\
(\%)\end{array}$ & $\begin{array}{l}\text { Expectation } \\
(\%)\end{array}$ \\
\hline 94137 & 1621 & $66(0.70 \%)$ & $302(3.2 \%)$ & 922 & 132 & 203 \\
words & $(17.22 \%)$ & & & $(9.80 \%)$ & $(1.41 \%)$ & $(2.16 \%)$ \\
\hline
\end{tabular}

As discussed above, belief evidentials means that the knowledge or information originates from the author/ speaker's belief or viewpoint, which renders the proposition with a tone of subjectivity. Therefore, the author will employ such kind of evidentials as less as possible. However, far from undermining the reliability of the academic research article, the use of belief can even provide a research direction for other scholars if the author is a prominent figure and influential in the academic field. For example, Saleh and Yazdan in example 1 use the belief I suggest and some readers may study the specific content following suggest. Reliability and expectation, which themselves imply subjective elements, are scarcely used for the sake of the establishment of the author's reliability.

The most popular evidentials in the academic articles is hearsay, followed by inference. The direct quotation and repot of the existing knowledge not only affirm the academic value of the previous researches but also support the author's claims. Besides, it should be noted that the employment of hearsay evidentials in academic articles in some cases implies the author's challenge to the existing academic achievements, in other words, the article aims to overthrow the previous theories. Under such circumstance, the author's reliability rests not only on evidentials but also on other factors. For example: 
Example 11: This result confirms claims made by Wood and Jones (1995) that there should be a match between the CSR initiative and the outcome measure. Beyond that, we may argue that....

Example 12: It marks a contrast with previous analyses of police-suspect interviews (see above). (Haworth, 2015)

In example 11 and 12, the phrases beyond that and marks a contrast with indicate that the studies in question are carried out based on the knowledge of the previous researches and furthermore. Furthermore, differences or process of the present study is shown through such a kind of review of the existing knowledge produced by previous researchers.

Inference based on fact and logical reasoning expresses the strictness and scrupulousness of the author, hence enhancing the reliability of the academic research article. Furthermore, the reliability of the author is closely related to the degree of certainty of the inference. In academic articles, the author is expected to refrain from words of uncertainty in case the reliability is thus damaged. It is found in this study that there are varying degrees of certainty of evidentials. For instance, definitely, certainly, demonstrate, clear and show represent high certainty, while possible, may, generally, often and sometimes display comparatively lower certainty. The author would appear to be overconfident and dominating to the readers if excessive evidential with high certainty is employed in the article, while overdue use of evidential with low certainty would also deprive the article of persuasiveness. Therefore, it is of great significance to properly weigh the proportion of the evidentials with high degree of certainty and those with low degree of certainty.

\section{Conclusion}

As a common linguistic phenomenon, evidentiality is represented by a variety of markers in academic research articles. Taking English academic research articles as an example, this study discusses the relationship between evidentiality and the construction of authorial identity from two aspects: the authority of the author, and the reliability of the author. It is found that both the 'source of knowledge' and the 'author's attitude towards knowledge' affect the author's authority. Meanwhile, the rational use of different types of evidentials and reasonable selection of various degrees of certainty help to improve the author's reliability. Belief, inference and reliability, though highly subjective, also play a part in strengthening the authority and reliability of the author provided that they are employed in a proper way. In a word, the rational employment of evidentials in academic research articles is conducive to the construction of authorial identity and meanwhile authorial identity is reflected in the choice of evidentials. It is hoped that this study can provide enlightenment and guidance for the writing of academic research article.

\section{References}

Aikhenvald, A., \& Dixon, R. M. W. (2003). Studies in Evidentiality. Amsterdam/ Philadelphia: John Benjamins Publishing Company. https://doi.org/10.1075/tsl.54

Aikhenvald, A. (2004). Evidentiality. Oxford: Oxford University Press.

Boas, F. (1947). Kwakiutl grammar, with a glossary of the suffixes. Transactions of the American Philosophical Society, (3). https://doi.org/10.2307/1005538

Bussmann, H. (1996). Routledged Dictionary of Language and Linguistics. London: Routledge.

Chafe, W., \& Nichols, J. (1986). Evidentiality: The Linguistic Coding of Epistemology. Norwood: Ablex.

Chafe, W. (1986). Evidentiality in English conversation and academic writing. In Chafe, W. and Nichols, W. (eds.). Evidentiality: The Linguistic Coding of Epistemology, 261-272. Norwood, NJ: Ablex.

Chen, Y. H., \& Baker, P. (2016). Investigating criterial discourse features across second language development: lexical bundles in rated learner essays, CEFR B1, B2 and C1. Applied Linguistics, 37(6), 849-880. https://doi.org/10.1093/applin/amu065

Delancey, S. (2003). The mirative and evidentiality. Journal of Pragmatics, 2001(3). https://doi.org/10.1016/S0378-2166(01)80001-1

Dynel, M. (2017). The irony of irony: Irony based on truthfulness. Corpus Pragmatics, 1(1), 3-36. https://doi.org/10.1007/s41701-016-0003-6

Gablasova, D., Brezina, V., Mcenery, T., \& Boyd, E. (2015). Epistemic stance in spoken L2 English: The effect of task and speaker style. Applied Linguistics, 38(5), 613-637. https://doi.org/10.1093/applin/amv055

Givoni, S., Giora, R., \& Bergerbest, D. (2013). How speakers alert addressees to multiple meanings. Journal of 
Pragmatics, 48(1), 29-40. https://doi.org/10.1016/j.pragma.2012.11.011

Haworth, K. (2015). The discursive construction of evidence in police interview: case study of a rape suspect. Applied Linguistics, 38(2), 174-214. https://doi.org/10.1093/applin/amv009

Hyand, K. (2002a). Authority and Invisibility: Authorial Identity in Academic Writing. Amsterdam / Philadelphia: John Benjamins Publishing Company.

Hyland, K. (1996). Writing without conviction? Hedging in science research articles. Applied Linguistics, 17(4). https://doi.org/10.1093/applin/17.4.433

Hyland, K. (2001a). Disciplinary Discourses: Social Interaction in Academic Writing. London: Longman.

Hyland, K. (2002b). Options of identity in academic writing. ELT Journal, 56(4). https://doi.org/10.1093/elt/56.4.351

Hyland, K. (2005b). Stance and engagement: A model of interaction in academic discourse. Discourse Studies, 7(2). https://doi.org/10.1177/1461445605050365

Ivanic, R. (1998). Writing and Identity: The Discoursal Construction of Identity in Academic Writing. Amsterdam/ Philadelphia: John Benjamins Publishing Company. https://doi.org/10.1075/swll.5

Ivanic, R., \& Camps, D. (2001). I am how I sound: Voice as self-representation in L2 writing. Journal of Second Language Writing, 10(1-2). https://doi.org/10.1016/S1060-3743(01)00034-0

Korat, O. (2018). Comparing comparatives: the argumentative force of comparative quantifiers. Corpus Pragmatics, 2(4), 399-423. https://doi.org/10.1093/applin/amu052

Malmström, H. (2014). Engaging the congregation: The place of metadiscourse in contemporary preaching. Applied linguistics, 37(4), 561-582. https://doi.org/10.1093/applin/amu052

Marchand, M., \& Parpart, J. (2003). Feminism, Postmodernism, Development: International Studies of Women and Place. London and New York: Routledge.

Matsuda, P. K., \& Tardy, C. M. (2007). Voice in academic writing: the rhetorical construction of author identity in blind manuscript review. English for Specific Purpose, 2007(26). https://doi.org/10.1016/j.esp.2006.10.001

Mithun, M. (1986). Evidential diachrony in Northern Iroquoian. In Chafe, W. \& Nichols (eds.). Evidentiality: The Linguistic Coding of Epistemology, 76-112. New Jersy: Alblex Publishing House.

Mushin, I. (2001). Evidentiality and Epistemological Stance: Narrative Retelling. Amsterdam/ Philadelphia: John Benjamins Publishing Company. https://doi.org/10.1075/pbns.87

Ouelette, M. (2008). Weaving strands of writer identity: Self as author and the NNES "plagiarist". Journal of Second Language Writing, 2008(17). https://doi.org/10.1016/j.jslw.2008.05.002

Palmer, F. (2001). Mood and Modality. Cambridge: Cambridge University Press. https://doi.org/10.1017/CBO9781139167178

Rocci, A. (2012). Modality and argumentative discourse relations: a study of the Italian necessity modal dovere. Journal of Pragmatics, 44(15), 2129-2149. https://doi.org/10.1016/j.pragma.2012.09.007

Tang, R., \& John, S. (1999). The "I" in identity: Exploring writer identity in student academic writing through the first person pro-noun. English for Specific Purpose, 1999(18). https://doi.org/10.1016/S0889-4906(99)00009-5

Wang, G. F., \& Yu, X. Y. (2011). A typological study of evidentiality in Chinese and English news discourse. Journal of Xi'an Foreign Languages University. 2011(2).

Willet, T. A. (1988). Cross-linguistic survey of the grammaticalization of evidentiality. Studies in English, 1988(12). https://doi.org/10.1075/sl.12.1.04wil

Yang, L. X. (2012). A comparative study of evidentiality in RAs in applied linguistics by NS and Chinese Writers. Open Journal of Modern Linguistics, 2012(4). https://doi.org/10.4236/ojml.2012.24018 